\title{
Dalcroze meets technology: integrating music, movement and visuals with the Music Paint Machine
}

\section{Luc Nijs}

To cite this article: Luc Nijs (2017): Dalcroze meets technology: integrating music, movement and visuals with the Music Paint Machine, Music Education Research

To link to this article: $h$ ttp://dx.doi.org/10.1080/14613808.2017.1312323

曲 Published online: 25 Apr 2017.

Submit your article to this journal ๘

Q View related articles $\longleftarrow$

View Crossmark data $₫$ 


\title{
Dalcroze meets technology: integrating music, movement and visuals with the Music Paint Machine
}

\author{
Luc Nijs \\ IPEM, Ghent University, Ghent, Belgium
}

\begin{abstract}
New interactive music educational technologies are often seen as a 'force of change', introducing new approaches that address the shortcomings (e.g. score-based, teacher-centred and disembodied) of the so-called traditional teaching approaches. And yet, despite the growing belief in their educational potential, these new technologies have been problematised with regard to their design, reception, implementation and evaluation. A possible way to optimise the realisation of the educational potential of interactive music educational technologies is to connect their use to music educational approaches that stood the test of time and as such may inspire technologies to become a bridge between tradition and innovation. This article describes an educational technology (the Music Paint Machine) that integrates the creative use of movement and visualisation to support instrumental music teaching and learning. Next, it connects this application to such an established music educational method, the Dalcroze approach. Through the lens of a set of interconnected aspects, it is shown how the Music Paint Machine's conceptual design aligns to the underlying principles of this approach. In this way, it is argued that integrating Dalcroze-inspired practices is a plausible way of realising the didactic potential of the system. An appendix with example exercises is provided.
\end{abstract}

\section{ARTICLE HISTORY}

Received 25 August 2016

Accepted 8 March 2017

\section{KEYWORDS}

Instrumental music education; interactive technologies; Dalcroze approach

\section{Introduction}

Music education is going through exciting times. Traditional approaches are being challenged and educators develop or introduce new approaches. This article proposes to connect emerging technology-based approaches to music educational approaches that stood the test of time and that, as such, may inspire new educational technologies to become a bridge between tradition and innovation. By way of example, it discursively elaborates on the possible connections between a specific technology, the Music Paint Machine (MPM, Nijs and Leman 2014), and a specific educational approach, the Dalcroze approach (Jaques-Dalcroze 2000; Greenhead, Habron, and Mathieu 2016; Juntunen 2016; Mead 1994; Wedin 2015).

One of the important driving forces behind ongoing music educational developments is the design of new technologies, provoked by the rapid development of the computer. Data can be processed, transformed and visually presented with an ever-increasing speed and computers become smaller and smaller. Also the way we interact with computers increasingly becomes (1) more natural by aligning it to the way we function in daily life without a computer, and (2) more social by shaping the interaction as much as possible in accordance with the way people communicate and by integrating social elements in the individual interaction (Dourish 2004). 
The new possibilities of computers and the new ways of interacting with the computer continuously inspire educators, scholars and engineers to develop computer applications for music education. In particular with regard to instrumental music education (incl. singing), an increasing amount of interactive technologies are designed that integrate (1) cutting edge sensing technologies and (2) the multimodal representation (e.g. visual and tactile feedback) of a performance in order to support different aspects of learning how to play an instrument. In this way different fundamentals of music performance can be addressed such as aural, technical/motor skills, expressive, structure/ notation/reading and presentation skills (Davidson 2012).

Many systems aim at monitoring sonic aspects of music performance. For example, several systems visualise sound characteristics (e.g. pitch, loudness, harmonic content and noisiness) in singing (e.g. WinsingAd: Welch et al. 2005; Sing \& See: Wilson et al. 2008) and instrument playing (e.g. Seeing sound: Ferguson 2006). Other systems focus on rhythm accuracy (e.g. drum-loop performance: Iwami and Miura 2007; Practice Space: Brandmeyer et al. 2006).

Performance monitoring is also integrated in intelligent tutoring systems that follow a musician's playing and provide immediate and customised instruction, without intervention of a human teacher (e.g. Imutus: Schoonderwaldt, Falkenberg Hansen, and Askenfeld 2004; Vemus: Fober, Letz, and Orlarey 2007). Additionally, performance monitoring is implemented in game-based applications (e.g. Guitarbots: Koskela 2015; MagnaQuest: Dubé, Kiss, and Bouldoire 2015).

A growing trend is the monitoring of physical aspects of a performance, based on the possibility of motion sensors to track musicians' posture and movements (e.g. Amir: Larkin et al. 2008; MusicJacket: Van Der Linden et al. 2011; Postrum: Dalgleish and Spencer 2014).

Very often these technologies are considered an added value to the teaching and learning process. Arguments to backup the belief in their educational potential concern, for example, the multimodal presentation of learning content as supporting the processing of learning content (de Jong 2010; Mayer et al. 1999; Sweller, Van Merrienboer, and Paas 1998), the use of objective measurement as a way to bypass the possible ambiguity of conventional verbal feedback (Hoppe, Sadakata, and Desain 2006; Howard et al. 2007), the facilitation of creating a powerful learning environment (Bransford 2000) and their appeal to young people (Burnard 2007; Prensky 2001; Upitis, Brook, and Abrami 2014; Wise, Greenwood, and Davis 2011).

However, despite the growing belief in the educational added value of technology, careful consideration is needed (see also: De Bruyckere, Kirschner, and Hulshof 2016). For example, many technologies integrate visual feedback but its use might, depending on the kind of visual feedback or the way it is used, cause degraded learning due to cognitive load (e.g. Mayer and Moreno 2003; Sadakata et al. 2008; Thorpe 2002), dependency (e.g. Ronsse et al. 2011; Schmidt 2008) or the stimulation of an internal focus (focus on how something is done with the body; e.g. Wulf and Lewthwaite 2009). Furthermore, educational technologies for instrumental music teaching easily fall into celebrating the seemingly unlimited possibilities of diverse technologies (e.g. motion sensors; software platforms) at the cost of pedagogical underpinnings. Often focusing on innovative monitoring possibilities, they easily support teacher-centred instruction (e.g. Bartel and Cameron 2004; Shernoff et al. 2003; Woody 2007) and a didactics of transmission and reproductive imitation (e.g. Young, Burwell, and Pickup 2003). Also, it should not be taken as evident that learners will be motivated by new technologies (e.g. De Bruyckere, Kirschner, and Hulshof 2016; Van den Beemt, Akkerman, and Simons 2011). Finally, studies involving educational technologies are often based on one-shot experiences, on a limited number of participants and a lack of in-depth analysis that supports the findings. Therefore, studies are needed that take these issues into account and that pave the way towards methodologically robust effect studies (e.g. Himonides and Purves 2010; Hoppe, Sadakata, and Desain 2006; Kirschner 2015).

Not surprisingly, different scholars have problematised educational technologies for their design (e.g. Manzo 2011), reception (e.g. Addessi, Pachet, and Caterina 2004) and implementation within the curriculum (e.g. Beckstead 2001; Hennessy, Ruthven, and Brindley 2005). Himonides and Purves (2010) even question whether the role of music technology for teaching and learning is actually well 
understood. They argue that the critical assessment of the effectiveness of these technologies should be based on empirical work that starts from well-informed theories about the alignment of technology with learning.

The educational potential of new technologies and their potential even to be a 'force for change' (Savage 2009) in the music educational domain arguably depends on two major factors. A first factor is the degree to which educational technologies are tailored to the human cognitive architecture that allows learning from the interaction with the environment (Leman and Nijs 2016). A crucial question is how educational technologies fit with the cognitive processes involved in music making and how this can be made effective for music teaching and learning, rather than merely providing students with a fun experience (Manzo 2011). To tackle this question, it is necessary to consider the processing components that frame the interaction with technology, such as working memory, long-term memory, schema-construction and schema-automation. The effectiveness of learning can then be assessed in terms of the ease with which information may be processed by the learner's cognitive architecture (Choi, van Merriënboer, and Paas 2014).

A second factor, and the topic of this article, is the connection to existing music educational approaches. Throughout the history of music education, different practices have emerged that have stood the test of time, displaying a profound insight in the nature of music learning. These practices are sometimes embedded in a broader pedagogical way of thinking (e.g. masterapprentice model) that is prone to critique on the basis of current pedagogical insights (e.g. Bowman 2002; Hennessy 2001; Lehmann, Sloboda, and Woody 2007). Nevertheless, it is important to acknowledge the rich knowledge base constituting the best practices that evolved throughout individual teachers' careers and within established educational traditions. Technologies may introduce new approaches to music education, but these 'tried-and-true methods [can be used] as a compass' (Dorfman 2013).

Several educational approaches appeal to recent insights about the essential role of the body in music learning (Bowman 2004; Leman 2007; Gruhn 2002). One such approach is Dalcroze Eurhythmics. Emile Jaques-Dalcroze (1865-1950) was a pianist, composer and professor at the Conservatoire of Geneva. He observed that many of his students cognitively understood musical concepts but were blocked in their musical expressiveness because they seemed to lack physical experience of musical concepts. Therefore, he developed a method that envisages the artistic embodiment of music by developing inner hearing and musical expression (Frego 2009; Juntunen and Westerlund 2001). In his approach, students learn to express and visualise music in a nuanced and meaningful manner through purposeful movement (Jaques-Dalcroze 2000).

Despite the seemingly natural connection between movement-based interactive technologies and the Dalcroze approach, no music educational technologies that are developed in order to implement or align to the Dalcroze approach were found. The work of Xiao et al. (2016) is an exception. Some scholars however do refer to Dalcroze in the context of educational technology. For example, Yu et al. (2010) used the Dalcroze approach in a teaching and learning experiment to test the DML system, a multimodal, dual-channel, multimedia learning system that provides efficient control over several multimedia objects (e.g. Word files, PowerPoint files, web pages). Dorfman (2013) also mentions Dalcroze as an approach that can guide the emergence and development of new, technology-inspired approaches to music instruction. Bauer (2014) mentions Dalcroze when writing on learning to improvise, on the importance of experiencing music before reading and writing it, and on teaching music listening. However, the Dalcroze approach is never directly linked to the design and use of a specific educational technology.

In view of the current emergence of movement-based educational technologies, this article advocates the idea that the Dalcroze approach to music learning can indeed be a 'compass', both in the design and didactic implementation of such technologies. It does so by describing the connection between an existing movement-based educational technology, the MPM and the Dalcroze approach. The MPM integrates the creative use of movement and visualisation in the instrumental music lesson (Nijs and Leman 2014). While this system is not designed with Jaques-Dalcroze's approach in mind, 
it has a high potential to integrate Dalcroze-inspired practices due to the alignment of the system's conceptual design to the underlying principles of the Dalcroze approach. This alignment is elaborated on through the lens of a set of interconnected aspects of the Dalcroze approach as outlined by Wedin (2015), providing both pedagogical and musicological arguments. Through this speculative connection (also inspired by the authors participation in Dalcroze workshops and sessions with Dalcroze practitioners using the MPM), this article aims at inspiring and inviting the music educational community of practice and, in particular, the Dalcroze community to engage in a joint effort of supporting and steering the design and educational implementation of interactive music educational technologies, and to collaborate in research projects in order to empirically investigate and possibly validate their educational potential. A first step could involve a phenomenological study on the experience of Dalcroze practitioners with an interactive technology, similar to the work of Van Der Merwe (2015) and Habron, Jesuthasan, and Bourne (2012). Based on these experiences, collaborative action research and, finally, intervention studies (e.g. comparative studies) can be designed that investigate the effect of Dalcroze-inspired practices with movement-based educational technologies on, for example, expressiveness, creativity, memory or rhythmical skills (see e.g. Brotz 2015; Taylor 1989; Wang 2008).

The following section (section 2) briefly describes the MPM, and elaborates on its educational goals and the features that support pursuing these goals. Section 3 explains how this technology aligns with the Dalcroze approach as a way of thinking (Wedin 2015, 217). An appendix to this article provides examples of Dalcroze-inspired practices with the MPM.

\section{The Music Paint Machine}

The MPM is an interactive educational technology that allows a musician to make a digital painting by playing music and by making various movements on a pressure-sensing coloured mat (www. musicpaintmachine.be). The system monitors and analyses the musician's sound and movements (feet and torso), and translates low-level features of music (duration, pitch and loudness) and movement (direction, footsteps and pressure) into the visual domain. Figure 1 presents an overview of the system's components.

For a more in-depth description of the system, the reader is referred to Nijs and Leman (2016).

The main objective of the MPM is to introduce an embodied-constructivist approach to instrumental music learning and teaching. Such an approach acknowledges the important role the body plays in musical signification processes and in the construction of musical knowledge (Leman 2007). This general objective is translated into a set of more concrete goals. A first goal is the development of musical creativity by inviting learners to be playful with musical parameters and by provoking an optimal experience (Addessi and Pachet 1999; Csikszentmihalyi 1990; Deliège and Wiggins 2006; Kratus 1991; Nijs et al. 2012; Woszczynski, Roth, and Segars 2002). A second goal is the development of an embodied understanding of music by integrating body movement as an essential component of musical expression and by providing a multimodal experience in which body movement and music converge into a common visual stimulus, that is, the digital painting (e.g. Bowman 2004; Leman 2007). A final goal is supporting the development of an optimal relationship between musician and musical instrument by using the combination of movement and music to control the multimodal interaction (Nijs, Lesaffre, and Leman 2013).

These goals are reflected in the four basic features of the system. A first feature is the use of creative visual feedback. By turning the screen into a canvas of exploration and experimentation, the MPM invites musicians to creatively use music, movement and visuals and to travel into unknown territories of music making in order to obtain a personalised outcome, namely the digital 'painting'. A second feature is the active use of body movements in order to generate a desired effect (e.g. determine drawing direction by turning the upper body). Musicians are invited to go beyond the corporeal dimension of merely instrumental gestures (to adequately execute the 


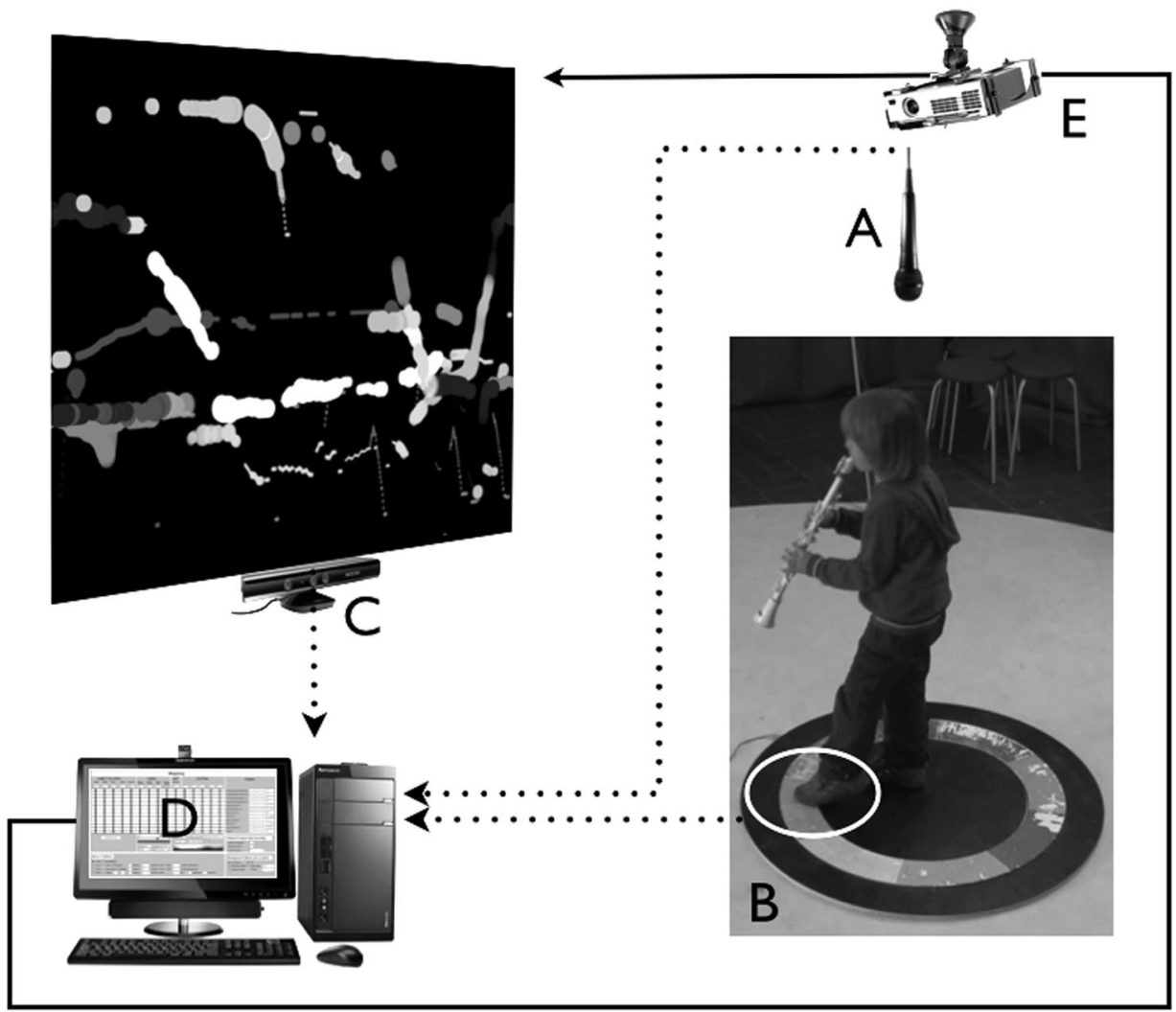

Figure 1. The different components of the MPM: a microphone $(A)$ to record the music, a pressure sensor mat (B) and a Kinect ${ }^{\oplus}$ camera $(C)$ to track the movements of the player, a computer with custom made software $(D)$ to analyse and compute incoming sound and movement data, and a beamer (E) to project the 'painting' on a screen or wall so the player can interact with the visualisation.

score) and to creatively use the body while playing a musical instrument. A third feature is the possibility to customise the system's configuration (e.g. mappings, user-settings) in function of specific educational content and goals (e.g. not mapping pitch when focusing on duration, adapt screen height to note range of a student). The system allows the design of a broad spectrum of activities that involve free exploration (experimenting with music, movement and visuals), guided exploration (task-based activities), gaming (challenge to use certain combinations of music and movement) or learning paths (methodically organised exercises) (see also Nijs and Leman 2014, 2016). In this way learners can move from exploration and experimentation towards carefully designed exercises. A fourth feature is the ability to tailor the system to the conditions of an optimal - or flow - experience in order to elicit such an experience (Chen, Wigand, and Nilan 1999; Csikszentmihalyi 1990; Nijs et al. 2012; Nijs and Leman 2014). The system allows the design of activities that have clear goals, carefully balance skills and challenge and provide immediate and unambiguous feedback on what is being played.

\section{Connecting the MPM to the Dalcroze approach}

The way the MPM is conceived and designed makes it appealing to integrate aspects of the Dalcroze approach to music learning. Evidently, there are important differences. In the next paragraphs these differences are elaborated on and some counterarguments are provided. 


\section{Differences}

First, the MPM advocates an approach that combines movement and playing the instrument. Within the Dalcroze approach, it is believed that training the kinaesthetic senses with the whole body, prior to learning to play an instrument, prepares students to express music in any form and with any instrument by making it much easier to apply musical knowledge and skills to an exterior instrument than with other methods where students begin directly at their instrument without any previous musical training (e.g. Manifold 2008; Schnebly-Black and Moore 2004). However, because the musical instrument is not a mere channel for the communication of musical meaning that is separate from the musical signification process (Nijs, Lesaffre, and Leman 2013), such linear view (first without, then with the instrument) possibly underestimates the impact of the musician-instrument relationship on bodily attunement to the music. The addition of instrumental gestures in the expressive interaction with music, as opposed to for example moving à la Dalcroze approach or dancing to music, changes the corporeal aspect of the interaction. Therefore, in the linear approach, the musician has to partially recalibrate the bodily attunement to the music. A possible alternative approach, as advocated by the MPM (Nijs and Leman 2014), is to integrate non-instrumental movements right from the start in the instrumental musical learning process to provoke a bodily attunement to the music's expressive affordances with the instrument at hand. Such an approach may allow developing musicians to explore their musical creativity and expressivity beyond the mere reproduction of a score, whereby the exploration of gestural (or: choreographic) ideas in relation to the music is the starting point of an individual perspective on the music rather than prior knowledge of established styles and performance conventions (Hubrich 2016; Nijs 2017; Schroeder and Newland 2013).

Second, the MPM introduces computer-generated visual feedback. In Dalcroze, visual feedback is very important but the most important visual source of information is the body itself. When moving to music, for each individual, the body becomes an instrument. When moving together, the body additionally becomes of vehicle of communication, showing aspects of the music such as tempo, rhythms, dynamics and aspects of melody (e.g. highest or lowest note of a phrase). In this way it can facilitate and support processes of entrainment (see also Repp and Su 2013) and, as such, of a mutual exchange of musical meaning. The important and powerful role of the body as a source of visual information might urge us to consider computer-generated visual feedback as unnecessary or distracting from what really counts (e.g. the music or the movements of another learner). However, Dalcroze classes also often integrate objects such as balls, hoops, ropes, sticks, stones or scarves to makes the music visible and concrete (Wedin 2015). For example, pathways on the floor can show aspects of melody (e.g. intervals represented by distance between beanbags) or using different materials (e.g. rope vs. stick) might provoke different kinds of expressive movements to music. Additionally, the use of objects facilitates and supports the use of movement, bringing attention outside the body and allowing the body to just follow/imitate the object.

The introduction of the MPM's visual feedback can be seen as introducing an object among other objects that brings in some particularities. Because it is based on real-time monitoring and visualisation, it is a dynamic and interactive object that at the same time captures the time course of the music by painting its trace on the screen, showing a kind of musical map as the enactive representation of the tight connection between music and movement (see also Blair [2008]). Dots, lines, shapes and colours become objects within an object that make the music visible and concrete.

Third, the MPM has an impact on the spatial experience in the classroom (see also Nijs and Leman [2014] on proxemics). An individual learner's interaction with the MPM reduces space to the limits of the coloured pressure-sensing mat. At this point the individual bodily interaction with the MPM is non-locomotor. Furthermore, since the movements are tracked with a Kinect camera, while somebody is painting it must be avoided that the body tracking is disturbed (e.g. by walking in between camera and tracked learner). But moving through space is an important part of the Dalcroze approach. Using a diversity of locomotor and non-locomotor movement patterns to align to the music, the approach emphasises large muscle movement and exploration of space, time and 
energy (Bachman 1991; Mead 1994). Thereby the spontaneous use of space is essential. Here, the MPM could interfere with the typical Dalcrozian use of space.

The above-described differences regarding the spatial aspects of interacting with the MPM mainly concern a situation in which an individual learner uses the system. However, when implemented in a collaborative setting the interaction can be embedded in a practice that involves the combination of non-locomotor and locomotor movements (see exercises in the Appendix).

\section{Similarities}

The above-described differences may lead to the tentative conclusion that the MPM is actually not compatible with the Dalcroze approach. Some might even think that no modern technologies at all are compatible with this approach. However, as will be illustrated in this section, the MPM appeals to the basic tenets of Dalcroze's philosophy on the basis of its specific features.

According to Wedin $(2015,217)$, the Dalcroze approach is not so much a set of exercises as it is an attitude, a way of thinking that is implemented through specific strategies and on the basis of coherent thinking. Here, an important resonance between the way of thinking in the Dalcroze approach and the way of thinking with the MPM can be found. Paraphrasing Wedin $(2015,217)$, one could say that '[exercises with the MPM] are activities that can be performed for a variety of reasons, in a variety of ways, with a variety of objectives' but that 'the most important aspect of [using the MPM] is not the exercises but the tactics, the strategies and the way of thinking'.

Wedin (2015, Chapter 11) describes the Dalcroze approach on the basis of a set of interconnected aspects that affect each other. In the following paragraphs, the MPM is related to each of these aspects. The reader is referred to the appendix for some exercises that demonstrate how the tenets described below are implemented in some exercises that are inspired by the Dalcroze approach.

\section{Multiple senses}

Musical experience is not a mere auditory experience but appeals to multiple senses (Leman 2007). In the Dalcroze approach music is therefore approached through different senses: hearing the music, seeing others move to the music, moving to the music with your own body and interacting with different materials (see also: Bachman 1991; Mead 1994; Schnebly-Black and Moore 2003). Through rhythmical activities, the exterior senses (hearing, seeing, touching and moving) are connected with interior activities in the brain (memory, memory retrieval, judgment, willpower and imagination) and learners develop the ability to express musical elements through body movement and as such to understand the music from within.

The MPM clearly subscribes to this multisensory integration, combining music, movement and image. By combining a creative use of visual feedback with the objective measurement of music and movement, it allows balancing between provoking exploration/experimentation and providing knowledge of performance (KP) or knowledge of results (KR). Within the context of instrumental teaching and learning, the 'exact' (based on objective measurement) visual representation (providing $\mathrm{KP}$ or KR) of music and movement has an important added value because the use of various movements might interfere with technical aspects of playing, such as tone production or intonation. Precisely this visually informed negotiation between the non-instrumental movement variations and instrumental gestures leads to the possibility of integrating different sensorimotor aspects involved in playing, namely personal style of moving, instrumental gestures and movement response to the music played (Nijs 2017).

\section{From different angles}

Imitation is a powerful aspect of learning and its acknowledgement often leads to a focus on repetition (Nehaniv and Dautenhahn 2007). Therefore, the Dalcroze approach also focuses on variation as a motor of learning. Indeed, learning about a certain (musical) content is deeper, more efficient and enjoyable when approached from different angles (playful interaction, improvising and different 
associated movements) (e.g. Brotz 2015; Ling Lo 2012; Runesson 2006). In addition, this approach also stimulates creativity (e.g. Greenhead, Habron, and Mathieu 2016; Habron, Jesuthasan, and Bourne 2012).

The MPM in itself provides a different angle to many aspects of the instrumental music learning process. Here, it is important to emphasise that the use of this educational technology is not an alternative to current approaches. Rather it serves a complementary role. And exactly in its complementarity it provides a different perspective to a specific learning content, adding movement and visualisation through one of the different modes of use. In addition, the flexibility of the MPM allows approaching the same learning content in different ways, by for example changing the mapping or the backgrounds, the colour patterns or the role one takes in collaborative practice with the system.

\section{Making the abstract concrete}

Because music does not always refer directly to specific events in the world, it is often experienced and approached as something rather abstract (Doğantan-Dack 2011). In combination with its evanescent nature it is sometimes difficult to grasp the music's meaning and to translate one's understanding of the music into adequate musical intentions that shape musical interaction. Therefore, music teachers often rely on verbal explanations, using for example structural analysis and metaphors (Meissner 2016; Schippers 2006). And yet, musical interaction is at the same time a very physical experience (Bresler 2004; Leman 2007; Leman and Nijs 2016). The Dalcroze approach acknowledges this bodily basis of musical interaction and addresses it to make the music concrete and thereby graspable - through movement activities, sometimes even integrating objects and images. For example, abstract aspects of timing (e.g. note value) are made more concrete by turning them into aspects of space (e.g. size of arm movement, step size while walking).

The MPM also offers a way to make the abstract more concrete. The system allows experimenting and playing with different music and movement parameters, both visualised on the screen. In this way learners first experience elements such as duration or loudness, pitch intervals or lateral movement as concretised through a visual representation (e.g. length or thickness of a line for dynamics, height on the screen for pitch and drawing direction for phrasing).

\section{Show what you hear/see/imagine}

In music performance, awareness of the music, of other players, of yourself is extremely important to turn musical ideas into music. It allows responding to the music, aligning with (e.g. in playing style) and responding (e.g. to on-the-spot musical initiative) to co-performers and to adjust one's playing when necessary. The Dalcroze approach very much appeals to this perceptual aspect of musical involvement. This is achieved by following three guiding principles or mottoes: (1) show (in movement or pictures) what you hear, (2) show (in sound, music or movement) what you see, and (3) show (in sound, music, movement or images) what you imagine (Wedin 2015, 15).

The MPM shows what is actually played and in that way it can help to even show what a learner might not hear yet (e.g. changes in intonation when playing crescendo). As such it can help to refine one's listening skills and thereby contribute to the learners' ability to 'show what they hear'. Tasks with the MPM can also invite to 'show what you see' by providing background images that address specific aspects of music or movement. A further possibility is to use one learner's painting as a kind of score for another learner.

\section{Impression-expression}

When playing music, there is a constant interaction between taking information in (listening, feeling) and translating ideas into the music (performing) while at the same time responding to the incoming information (Keller 2014). This interplay between impression and expression is an important element in the Dalcroze approach, especially in connection to the previous aspect (Show what you hear/see/imagine). For example, hearing or imagining music (impression) is translated into movement (expression) or seeing movement (impression) is translated into music (expression). 
Interestingly, with regard to this aspect Wedin points out the importance of the perceived balance between impression and expression in a learning/teaching situation. According to her, too much impression leads to oversaturation, too much expression leads to feeling drained.

The MPM may intensify the impression-expression interplay. By adding the visual component, the incoming information is enriched in two ways. First, the visual representation per se complements the musical experience. Second, the visual representation contains information on what is played and as such can contribute to the processing of the incoming information. By inviting learners to broaden the motor experience of playing music, the repertoire of expressive responses is enlarged. Moreover, the flexibility of the mapping (what is translated in what) can prevent oversaturation (e.g. not mapping a musical parameter) and exaggerated expression (e.g. limiting the extend of movement that is mapped).

\section{From the known to the unknown}

Current pedagogical insights emphasise the importance of constructing new knowledge on the basis of previously acquired knowledge (Pritchard and Woollard 2010). The Dalcroze approach integrates simple activities that belong to the action repertoire of most people, such as walking or clapping. These activities are first used with previously acquired musical knowledge (e.g. four beat measure) and then varied to introduce new learning content (e.g. five beat measure). In this way it is not only about learning something new, but also about learning to grasp (dis)similarities between what they already know and new learning content.

The basic idea of the MPM was to introduce something familiar, namely drawing, to stimulate a musical activity that is rather scarce in a predominantly score-based instrumental music education, namely improvisation (Nijs et al. 2010). Throughout the drawing or 'painting', children almost forget they are actually improvising and in this way they become more familiar with it, allowing them to also do it in other contexts. This didactic potential with regard to improvisation was acknowledged in a study on user experience with the MPM (Nijs et al. 2012). Additionally, the flexibility of the systems supports the design of both musical and motor tasks that allow proceeding from the known to the unknown. For example, new notes can be introduced through the comparison of visual models, or new step exercises can be introduced by adding elements (e.g. different colour combinations) to existing step movements (Nijs and Leman 2014, 2016).

\section{The staircase - going step-by-step}

Acknowledging the importance of the previous aspect implies a step-by-step approach to education, providing learners with clear goals every step of the way starting from knowledge acquired through a previous step (see also Van Merriënboer and Kirschner 2016). Of course, moving incrementally is a general pedagogical given, but one the Dalcroze approach clearly adheres to, always starting from simple tasks and gradually moving on to more complex tasks to eventually lead to the defined learning goal.

This step-by-step approach is easily adopted when using the MPM. Tasks can start very simple, first reducing the number of mapped parameters (e.g. no pitch or limited pitch range, only length of notes) and without the combination of motor and musical tasks. Then simple combinations can be introduced and further developed with increasing complexity (e.g. adding colours to be used to make more complex step exercises, expanding pitch range).

\section{My way - your way}

Learner autonomy and self-regulation are important aspects of the learning process (Greenhead, Habron, and Mathieu 2016; Juntunen 2016; McPherson and Renwick 2001). In the Dalcroze approach this is clearly acknowledged. Teaching is not about 'right and wrong' but about helping learners to express themselves in their own way, possibly inspired by the teacher and by other learners. This leads to the acceptance of variation and its acknowledgement as a powerful way to develop creativity. 
The MPM aims at supporting the development of learner autonomy and self-regulation. Each of the different modes offers the possibility to allow learners to perform a task in their own way. Especially in the free and the guided exploration modes, the MPM offers a creative space in which learners can experiment with music, movement and image without being preoccupied with what is right or wrong. Here, movements can be used that are unusual and even considered as detrimental to playing technique. But it is exactly throughout the experimenting that awareness grows and learners find out how movement affects playing, and discover what works and what does not work. In the same way learners can experiment with musical parameters, finding out how they are connected (e.g. play louder induces play faster or changes intonation) and gaining control through experimenting with these connections in function of painting something particular.

\section{Your own level}

Providing learners with tasks at the right level of difficulty is an important aspect of teaching. Such tasks necessarily are challenging but within reach of the learner's current skills. In this way both frustration and boredom are avoided (Csikszentmihalyi 1990). Moreover, learners need to be able to set their own goals and challenges, individually or in collaboration with teacher and peers. Activities in the Dalcroze approach are always carefully designed, allowing learners to proceed at their own pace but challenged in a playful way.

Because flow theory guided the design of the MPM (Nijs et al. 2012), this aspect is very important and implemented on the basis of the system's flexibility. Indeed, the settings of the system (e.g. note range, loudness range, and speed) can be configured to the learner's individual skills. Additionally, tasks with the MPM can be designed and presented in such a way that they allow learners to set their own goals with regard to particular aspects of the task (e.g. choose colours, drawing direction, and notes).

\section{Freedom within frames}

Taking into account the previous aspects, it is important to find a balance between freedom and constraints (Greenhead and Habron 2015; Kirschner, Sweller, and Clark 2006). Too much freedom can turn an activity into a frustrating experience due to a lack of clear goals. Clearly defining the frames in which a certain degree of freedom is present provokes a feeling of security and self-confidence. Moreover it stimulates creativity by challenging learners to negotiate between spontaneity and limitations and by stimulating variation in coping with the limitations.

The MPM, and especially its guided exploration and game mode, provide such frames in which the learner is given freedom to explore, experiment and play with music, movement and image. Sometimes the frame can be motor-oriented (e.g. using specific colours thereby defining a specific movement pattern as frame), leaving a creative space for musical explorations (e.g. choose notes, dynamics, and drawing direction). Sometimes the frame can be music-oriented (e.g. using a pentatonic scale as musical frame), leaving a creative space to explore and experiment with movement (e.g. with the feet to choose colours, with the upper body to influence for example transparency or saturation of the colours).

\section{1-2-4-everyone}

Collaborative learning is known to create a powerful learning environment (Bransford 2000). In the Dalcroze approach is it a common practice to vary group size and constellations in order to add variety and dynamics to a lesson (motivation), to provide different perspectives to the learning content and to promote cooperation (social skills). At the same time opportunities for individual processing are integrated in a lesson.

The MPM started out as a system to individually engages with. However, throughout a longitudinal study (Nijs and Leman 2014) it became clear that the system could be integrated in collaborative practices (this was also experienced in a session with Dalcroze practitioners and in different sessions with pre-service teachers). While one or more students are playing, another can use the coloured 
pressure mat to, for example, colour phrases or certain motives (cf. show what you hear). Or, the movements of the student who interacts with the MPM can be imitated by other students in the classroom and, later on, be transformed into something of their own when using those movements to make a painting themselves. Also, a painting by one student can be used as a 'score' for other students (cf. show what you see).

\section{Leading-following}

Learner-centeredness is an important aspect of a powerful learning environment (Bransford 2000). It fosters knowledge construction and skill acquisition on the basis of the learners' current knowledge and skills, their personal interests and beliefs, and their attitudes. The Dalcroze approach adopts a learner-centeredness by delegating leadership in the group on the basis of turn taking in leading and following. For example, a student can be invited to take the lead in showing a bodily response to music (e.g. perform a stepping pattern accompanied by certain arm movements) that can be mirrored by the other students. Next, the leading student can make changes in the movement patterns that address, for example, another level of subdivision or implement an augmentation or diminution of a rhythmic pattern. In this way, learners have the opportunity, when leading, to set their own level and to do it in their own way. When following, they can be challenged to move beyond one's own way and to break free from habitual patterns. This is vital to developing creativity (e.g. Green 2002). Importantly, when stepping back from leading, the teacher can observe the students in the different roles and in this way gather the necessary knowledge to differentiate between learners.

The MPM places the learner's experience in the centre of the learning process, providing opportunities to take initiative and to set one's own goals. As such they can take the lead and become responsible for their enquiry-based learning and ultimate meaning making. The goal of making specific paintings often leads to a musical problem to which they have to find a solution. Such occasions are ideal to evoke collaborative learning through which learners look for a possible solution and the way to achieve this solution. Both teacher and system can scaffold their learning. Furthermore, in collaborative practices with the MPM one student can take the lead by triggering another student's interaction with the system on the basis of specific musical elements (e.g. certain notes trigger certain colours) or specific movements (e.g. small/large movements trigger soft/loud notes).

\section{Imitation/transformation}

Imitation is a basic human mechanism for learning (Tsukerman 2016). It allows learning new behaviour but also sharing another individual's experiences. The former allows expanding one's own repertoire of actions. The latter leads to knowledge about other individuals' intentions. Yet imitation is sometimes viewed as a low-level form of learning. Deep learning is believed only to occur when newly acquired knowledge is applied to solve new problems. Therefore learners need to transform learning content in something of their own, for example by translating it into another modality (e.g. music into movement) (Washburn 2010). In the Dalcroze approach, imitation is a fundamental exercise (Urista 2016). However, it is never used as a way to adopt the 'do as I do' approach of traditional education (Bachman 1991). Rather it is about becoming aware of the tendency to imitate by contagion, thereby opening the door not only to variation but also to voluntary imitation. Imitation is used in canon exercises and in exercises to train skills of observation, concentration and memory (e.g. Schnebly-Black and Moore 2003).

Through its different modes of use, practices with the MPM can use imitation to introduce certain learning content and then support the transformation of newly acquired knowledge or skills. For example, an imitation-based exercise can impose certain colours to induce a step pattern. Next, 
this newly acquired step pattern can be applied in different melodies, during improvisation or with different colours. Or learners can play the same melody, choosing their own accompanying colour pattern.

\section{Experiencing - exploring/experimenting - reflecting}

The Dalcroze approach subscribes to the idea that indeed it is almost only possible for learners to verbalise and theorise once they have a sensory experience upon which they can reflect. Once provided with such an experience, it is important to engage in exploration and experimentation.

The MPM provides students with compelling experiences in which music, movement and image merge and provide learners with a visually augmented perspective on their playing music. First, students experience the effect of their playing on the visuals (e.g. play louder gives a thicker line, bending changes colour saturation). This typically happens in the free exploration mode, in which they can also start experimenting and exploring these effects. Moreover, when setting their own goals (e.g. draw a circle) they need to reflect on how to use the different effects. This combination of exploration/experimentation with reflection is deployed in the guided exploration and gaming modes. Often the reflection emerges from a problem (exemplified in a specific task) that challenges the students and stimulates them to alternate in their attempts to collaboratively seek a solution to the problem. The learning path mode offers fewer opportunities for exploration but fosters reflection on very specific musical aspects (e.g. pattern of tones and semitones in a scale).

\section{Sound before symbol}

Instrumental music teaching is very often based on the reproduction of written music. Students have to learn to decode notation (read) and replicate (play) the composer's intentions, often as understood by the teacher. However, such an emphasis on notation might lead to a decrease in the sensitivity that allows the spontaneous perception of patterns when listening to music (McPherson and Gabrielsson 2002). Consequently, playing becomes a question of coupling notation to fingerings instead of sounds and practice habits might not be driven by the ear (Lehmann, Sloboda, and Woody 2007). This approach is exactly what the Dalcroze approach seeks to counter, by developing a basic grasp of the different aspects of music through movement-based activities that involve singing and listening without relying on scores.

The MPM subscribes to such a 'sound to sign' approach. It allows students to experience different aspects of music (e.g. duration, pitch, and loudness) through a kind of enactive mode of representation that in a way can function as an alternative to the symbolic way of representing those aspects (notation). Exercises and modes of use can be implemented in such a way that the symbolic representation of music is experienced as a logical step.

\section{The scarlet thread}

Effective teaching relies on lessons that are well-structured in function of specific learning content (e.g. Duke and Chapman 2011). In the Dalcroze approach careful attention is given to the 'choreography' of a lesson, making sure that at the end of a lesson the students perform something of their own, a form (using elements from the whole lesson).

The MPM can be integrated into such a well-structured lesson. Moreover, experiences with the MPM can be used as structuring events of a lesson. Typically, the classroom use of the MPM takes about 20-30 minutes in a one-hour lesson. A good design of a lesson with the MPM implies a well-considered use of the different play modes (free and guided exploration, gaming, and learning path). Here the protean nature of the system is a challenge to the teacher, who is faced with endless possibilities but needs to select and design the best-suited exercises in function of the lesson content, embedded within a learning trajectory over different lessons. 


\section{Conclusion}

This paper presented an education technology, the MPM, and discursively elaborated on the way in which it can be connected to an established music educational approach, the Dalcroze approach. This elaboration can be useful in several ways. First, it introduces an illustrative example of how educational technologies can be connected to a well-established music educational approach by focusing on the basic principles that underlie this approach. Arguably, making such connections is vital to the development of movement-based music educational technologies. The experiential knowledge of practice can provide a rich and solid knowledge base for the design and classroom use of music educational technologies. The elaboration of the alignment between the Dalcroze approach and the MPM can contribute to the establishment of well-informed theories about the alignment of technology with learning (Himonides and Purves 2010). Second, technologies such as the MPM can provide enriching experiences within such well-established approaches, providing a 'different angle' to look at one's own established method. But designing the technology with such an approach in mind or developing classroom practices with the technology may also provoke new insights on how and what to teach without the technology (see also Nijs and Leman 2014). Third, by trying to connect technologies to existing practices, insights may emerge that provide novel ways to address music educational instruction.

The elaboration of the MPM-Dalcroze connection as presented in this article has led to fruitful collaborations with Dalcroze practitioners that enable the further development of a set of practices that (1) forms a solid basis for the further development of the system and (2) provides interventions for forthcoming empirical studies.

Hopefully, the elaborated example in this article may inspire other scholars and educators to look for ways in which new technologies can connect to existing well-established practices, to look beyond such practices and to find new paths that are inspired by technology, but driven by pedagogy!

\section{Acknowledgements}

This research was conducted in the framework of the EmcoMetecca project, granted by Ghent University (Methusalem-BOF council) to Prof. Dr. Marc Leman.

The author wishes to thank Carine De Vinck and her team of Dalcroze teachers at the Institut Dalcroze Belgique, and Eva Wedin, Lina Van Dooren, Emma Shubin and Michael Joviala for the inspiring collaboration and conversations. Also many thanks to the anonymous reviewers for their constructive and critical assessment of the manuscript.

\section{Disclosure statement}

No potential conflict of interest was reported by the author.

\section{Notes on contributor}

Luc Nijs holds MA's in Music Performance and Philosophy, and a PhD in Musicology. He is currently postdoctoral researcher at IPEM (Ghent University, BE) and lecturer in Music Educational Technology at the Royal Conservatory The Hague (NL) and Luca School of Arts Leuven (BE). His research focuses on the musician-instrument relationship, on the role of body movement in the instrumental learning process and on the role of technology in provoking an embodied approach to instrumental music education. His PhD project received the EAPRIL Best Research and Practice Project Award 2012.

\section{ORCID}




\section{References}

Addessi, A. R., and F. Pachet. 1999. "Experiments with a Musical Machine: Musical Style Replication in 3 to 5 Year Old Children.” British Journal of Music Education 22 (01): 21-46. doi:10.1017/S0265051704005972.

Addessi, A. R., F. Pachet, and R. Caterina. 2004. "Children Confronting an Interactive Musical System.” Paper presented at the 8th International Conference on Music Perception \& Cognition (ICMPC8), Adelaide, Australia, August 3-7.

Bachman, M.-L. 1991. Dalcroze Today: An Education Through and into Music. New York: Oxford University Press.

Bartel, L., and L. Cameron. 2004. "From Dilemmas to Experience: Shaping the Conditions of Learning." In Questioning the Music Education Paradigm, edited by L. Bartel, 39-62. Toronto: Canadian Music Educator's Association.

Bauer, W. I. 2014. Music Learning Today: Digital Pedagogy for Creating, Performing, and Responding to Music. New York: Oxford University Press.

Beckstead, D. 2001. “Will Technology Transform Music Education?” Music Educators Journal 87 (6): 44-49. doi:10. 2307/3399692.

Blair, D. 2008. "Do You Hear What I Hear? Musical Maps and Felt Pathways of Musical Understanding." Visions of Research in Music Education 11: 1-23.

Bowman, W. 2002. "Educating Musically." In The New Handbook of Research on Music Teaching and Learning, edited by R. Colwell and C. Richardson, 63-84. New York: Oxford University Press.

Bowman, W. 2004. "Cognition and the Body: Perspectives from Music Education." In Knowing Bodies, Moving Minds: Towards Embodied Teaching and Learning, edited by L. Bresler, 29-50. Dordrecht: Kluwer Academic.

Brandmeyer, A., D. Hoppe, M. Sadakata, R. Timmers, and P. Desain. 2006. "PracticeSpace: A Platform for Real-time Visual Feedback in Music Instruction." Paper presented at the 9th International Conference on Music Perception and Cognition, Bologna, Italy, August 22-26.

Bransford, J. 2000. How People Learn: Brain, Mind, Experience, and School. Washington, DC: National Academies Press.

Bresler, L., ed. 2004. Knowing Bodies, Moving Minds: Towards Embodied Teaching and Learning. Dordrecht: Kluwer Academic Publishers.

Brotz, T. 2015. "Dalcrozian Piano Pedagogy and Cognitive Motor Learning Theory." American Dalcroze Journal 41 (3): 22-29.

Burnard, P. 2007. "Creativity and Technology: Critical Agents of Change in the Work and Lives of Music Teachers." In Music Education with Digital Technology, edited by J. Finney and P. Burnard, 131-141. London: Continuum.

Chen, H., R. T. Wigand, and M. Nilan. 1999. "Optimal Experience of Web Activities." Computers in Human Behavior 15 (5): 585-608. doi:10.1016/ S0747-5632(99)00038-2.

Choi, H.-H., J. J. G. van Merriënboer, and F. Paas. 2014. "Effects of the Physical Environment on Cognitive Load and Learning: Towards a New Model of Cognitive Load.” Educational Psychology Review 26 (2): 225-244. doi:10.1007/ s10648-014-9262-6.

Csikszentmihalyi, M. 1990. Flow: The Psychology of Optimal Experience. New York: Harper \& Row.

Dalgleish, M., and S. Spencer. 2014. "Postrum: Developing Good Posture in Trumpet Players through Directional Haptic Feedback." Paper presented at the 9th Conference on International Musicology (CIM14), Berlin, Germany, December 4-6.

Davidson, J. W. 2012. “The Role of Bodily Movement in Learning and Performing Music.” In The Oxford Handbook of Music Education, edited by G. E. McPherson, and G. F. Welch, 1769-782. New York, NY: Oxford University Press.

De Bruyckere, P., P. A. Kirschner, and C. D. Hulshof. 2016. “Technology in Education: What Teachers Should Know.” American Educator 40 (1): 12-18.

Deliège, I., and G. Wiggins. 2006. Musical Creativity: Multidisciplinary Research in Theory and Practice. New York: Psychology Press.

Doğantan-Dack, M. 2011. "In the Beginning Was Gesture: Piano Touch and the Phenomenology of the Performing Body." In New Perspectives on Music and Gesture, edited by A. Gritten and E. King, 243-265. Farnham, Surrey: Ashgate.

Dorfman, J. 2013. Theory and Practice of Technology-Based Music Instruction. New York: Oxford University Press.

Dourish, P. 2004. Where the Action Is: The Foundations of Embodied Interaction. Cambridge, MA: The MIT Press.

Dubé, F., J. Kiss, and H. Bouldoire. 2015. "Gamification and Learner Engagement: A " Learning the Violin » Implementation Interface Example." Paper presented at the LTM21 / AEM21 Conference, Montreal, Canada, November 5-7.

Duke, R. A., and D. L. Chapman. 2011. "Changing Learners: The Nature of Expertise in Music Teaching.” In Advances in Social-psychology and Music Education Research, edited by P. Madura Ward-Steinman, 29-38. London: Routledge.

Ferguson, Sam. 2006. "Learning Musical Instrument Skills Through Interactive Sonification.” Paper presented at the 2006 conference on New interfaces for musical expression (NIME06), Paris, France, June 4-8.

Fober, T., S. Letz, and Y. Orlarey. 2007. "VEMUS-Feedback and Groupware Technologies for Music Instrument Learning." Paper presented at the 4th International Sound and Music Computing Conference, Lefkada, Greece, July 11-13. 
Frego, R. J. D. 2009. “Plastique Animée: A Dance Genre and a Means to Artistry.” Le Rythme, 100 ${ }^{\text {th }}$ Anniversary Issue: 87-89.

Green, J. 2002. "Somatic Knowledge: The Body as Content and Methodology in Dance Education." Journal of Dance Education 2 (4): 114-118. doi:10.1080/15290824.2002.10387219.

Greenhead, K., and J. Habron. 2015. “The Touch of Sound: Dalcroze Eurhythmics as a Somatic Practice.” Journal of Dance \& Somatic Practices 7 (1): 93-112.

Greenhead, K., J. Habron, and L. Mathieu. 2016. "Dalcroze Eurhythmics: Bridging the Gap Between the Academic and Practical Through Creative Teaching and Learning." In Creative Teaching for Creative Learning in Higher Music Education, edited by E. Haddon and P. Burnard, 211-226. Oxford: Routledge.

Gruhn, W. 2002. "Phases and Stages in Early Music Learning. A Longitudinal Study on the Development of Young Children's Musical Potential." Music Education Research 4 (1): 51-71. doi:10.1080/14613800220119778.

Habron, J., J. Jesuthasan, and C. Bourne. 2012. Moving into Composition - The Experiences of Student Composers During a Short Course of Dalcroze Eurhythmics. Coventry: Coventry University.

Hennessy, S. 2001. "Research and Development in Music Education.” In Issues in Music Teaching, edited by C. Philpott and C. Plummeridge, 238-251. London: Routledge.

Hennessy, S., K. Ruthven, and S. Brindley. 2005. “Teacher Perspectives on Integrating ICT into Subject Teaching: Commitment, Constraints, Caution, and Change.” Journal of Curriculum Studies 37 (2): 155-192. doi:10.1080/ 0022027032000276961.

Himonides, E., and R. Purves. 2010. “The Role of Technology.” In Music Education in the 21st Century in the United Kingdom: Achievements, Analysis and Aspirations, edited by S. Hallam and A. Creech, 29-50. London: Institute of Education, University of London.

Hoppe, D., M. Sadakata, and P. Desain. 2006. "Development of Real-time Visual Feedback Assistance in Singing Training: A Review.” Journal of Computer Assisted Learning 22 (4): 308-316. doi:10.1111/j.1365-2729.2006. 00178.x.

Howard, D., J. Brereton, G. Welch, E. Himonides, M. DeCosta, J. Williams, and A. Howard. 2007. “Are Real-time Displays of Benefit in the Singing Studio? An Exploratory Study.” Journal of Voice 21 (1): 20-34. doi:10.1016/j. jvoice.2005.10.003.

Hubrich, S. 2016. “The Performer's Body in Creative Interpretations of Repertoire Music." Arts and Humanities in Higher Education 15 (3-4): 337-352. doi:10.1177/1474022216647711.

Iwami, N., and M. Miura. 2007. "A Support System for Basic Practice of Playing the Drums." Paper presented at the International Computer Music Conference, Copenhagen, Denmark, August 27-31.

Jaques-Dalcroze, E. 2000. Rhythm, Music \& Education. 5th ed. London: The Dalcroze Society.

de Jong, T. 2010. "Cognitive Load Theory, Educational Research, and Instructional Design: Some Food for Thought.” Instructional Science 38 (2): 105-134. doi:10.1007/s11251-009-9110-0.

Juntunen, M.-L. 2016. “The Dalcroze Approach: Experiencing and Knowing Music through Embodied Exploration.” In Approaches to Teaching General Music: Methods, Issues, and Viewpoints, edited by C. R. Abril and B. M. Gault, 141-167. New York, NY: Oxford University Press.

Juntunen, M.-L., and H. Westerlund. 2001. "Digging Dalcroze, or, Dissolving the Mind-Body Dualism: Philosophical and Practical Remarks on the Musical Body in Action.” Music Education Research 3 (2): 203-214. doi:10.1177/ 1048371311428979.

Keller, P. 2014. "Ensemble Performance: Interpersonal Alignment of Musical Expression.” In Expressiveness in Music Performance: Empirical Approaches Across Styles and Cultures, edited by D. Fabian, R. Timmers, and E. Schubert, 260-282. New York, NY: Oxford University Press.

Kirschner, P. A. 2015. “Do We Need Teachers as Designers of Technology Enhanced Learning?.” Instructional Science 43 (2): 309-322. doi:10.1007/s11251-015-9346-9.

Kirschner, P. A., J. Sweller, and R. Clark. 2006. "Why Minimal Guidance During Instruction Does not Work: An Analysis of the Failure of Constructivist, Discovery, Problem-based, Experiential and Inquiry-based Teaching." Educational Psychologist 41: 75-86. doi:10.1207/s15326985ep4102_1.

Koskela, T. 2015. “Choosing Juice: Enabling Fun in Games through Better Visual Design.” Unpublished Bachelor thesis, Tampere University of Applied Sciences, Tampere.

Kratus, J. 1991. “Growing with Improvisation.” Music Educators Journal 78 (4): 35-40. doi:10.2307/3398335.

Larkin, O., T. Koerselman, B. Ong, and K. Ng. 2008. "Sonification of Bowing Features for String Instrument Training." Paper presented at the 4th International Conference on Auditory Display, Paris, France, June 24-27.

Lehmann, A. C., J. A. Sloboda, and R. H. Woody. 2007. Psychology for Musicians: Understanding and Acquiring the Skills. New York, NY: Oxford University Press.

Leman, M. 2007. Embodied Music Cognition and Mediation Technology. London: The MIT Press.

Leman, M., and L. Nijs. 2016. "Cognition and Technology for Instrumental Music Learning." In The Routledge Companion to Music, Technology \& Education, edited by A. King, E. Himonides, and A. Ruthman, 23-36. London: Routledge.

Ling Lo, M. 2012. Variation Theory and the Improvement of Teaching and Learning. Göteborg: Acta Universitatis Gothoburgensis. 
Manifold, L. H. 2008. Applying Jaques-Dalcroze's Method to Teaching Musical Instruments and Its Effect on the Learning Process. Accessed 31 July 2015. http://manifoldmelodies.com/docs/Manifold_Dalcroze_voice.pdf.

Manzo, V. J. 2011. Max/MSP/Jitter for Music: A Practical Guide to Developing Interactive Music Systems for Education and More. New York, NY: Oxford University Press.

Mayer, R. E., and R. Moreno. 2003. "Nine Ways to Reduce Cognitive Load in Multimedia Learning." Educational Psychologist 38 (1): 43-52. doi:10.1207/S15326985EP3801_6.

Mayer, R. E., R. Moreno, M. Boire, and S. Vagge. 1999. "Maximizing Constructivist Learning from Multimedia Communications by Minimizing Cognitive Load.” Journal of Educational Psychology 91 (4): 638. doi:10.1037/ 0022-0663.91.4.638.

McPherson, G. E., and A. Gabrielsson. 2002. "From Sound to Sign." In The Science and Psychology of Music Performance: Creative Strategies for Teaching and Learning, edited by R. Parncutt and G. McPherson, 99-116. New York, NY: Oxford University Press.

McPherson, G. E., and J. M. Renwick. 2001. “A Longitudinal Study of Self-regulation in Children's Musical Practice.” Music Education Research 3 (2): 169-186. doi:10.1080/14613800120089232.

Mead, V. H. 1994. Dalcroze Eurhythmics in Today's Music Classroom. New York, NY: Schott Company.

Meissner, H. 2016. "Instrumental Teachers' Instructional Strategies for Facilitating Children's Learning of Expressive Music Performance: An Exploratory Study." International Journal of Music Education. doi:10.1177/ 0255761415619390.

Nehaniv, C. L., and K. Dautenhahn, eds. 2007. Imitation and Social Learning in Robots, Humans and Animals: Behavioural, Social and Communicative Dimensions. Cambridge: Cambridge University Press.

Nijs, L. 2017. "The Merging of Musician and Musical Instrument: Incorporation, Presence and the Levels of Embodiment." In The Routledge Companion to Embodied Music Interaction, edited by M. Lesaffre, P.-J. Maes, and M. Leman, 49-57. London: Routledge.

Nijs, Luc, Pieter Coussement, Bart Moens, Denis Amelinck, Micheline Lesaffre, and Marc Leman. 2012. "Interacting with the Music Paint Machine: Relating the Constructs of Flow Experience and Presence." Interacting with Computers 24: 237-250. doi:10.1016/j.intcom.2012.05.002.

Nijs, L., P. Coussement, C. Muller, M. Lesaffre, and M. Leman. 2010. “The Music Paint Machine. A Multimodal Interactive Platform to Stimulate Musical Creativity in Instrumental Practice." Paper presented at the Second International Conference on Computer Supported Education, Valencia, Spain, April 7-10.

Nijs, Luc, and Marc Leman. 2014. "Interactive Technologies in the Instrumental Music Classroom: A Longitudinal Study with the Music Paint Machine." Computers \& Education 73: 40-59. doi:10.1016/j.intcom.2012.05.002.

Nijs, Luc, and Marc Leman. 2016. "Performing with the Music Paint Machine: Provoking an Embodied Approach to Educational Technology.” In Music, Technology \& Education: Critical Perspectives, edited by Andrew King, and Evangelos Himonides, 225-242. London: Ashgate Psychology of Music Series.

Nijs, L., M. Lesaffre, and M. Leman. 2013. “The Musical Instrument as a Natural Extension of the Musician.” In Music and Its Instruments, edited by M. Castellengo and H. Genevois, 467-484. Sampzon: Editions Delatour France.

Prensky, M. 2001. "Digital Natives, Digital Immigrants Part 1.” On the Horizon 9 (5): 1-6.

Pritchard, A., and J. Woollard. 2010. Psychology for the Classroom: Constructivism and Social Learning. New York, NY: Routledge.

Repp, B. H., and Y.-H. Su. 2013. "Sensorimotor Synchronization: A Review of Recent Research (2006-2012)." Psychonomic Bulletin \& Review 20 (3): 403-452. doi:10.3758/s13423-012-0371-2.

Ronsse, R., V. Puttemans, J. P. Coxon, D. J. Goble, J. Wagemans, N. Wenderoth, and S. Swinnen. 2011. "Motor Learning with Augmented Feedback: Modality-Dependent Behavioral and Neural Consequences." Cerebral Cortex 21 (6): 1283-1294. doi:10.1093/cercor/bhq209.

Runesson, U. 2006. "What Is It Possible to Learn? On Variation as a Necessary Condition for Learning." Scandinavian Journal of Educational Research 50 (4): 397-410. doi:10.1080/00313830600823753.

Sadakata, M., D. Hoppe, A. Brandmeyer, R. Timmers, and P. Desain. 2008. "Real-time Visual Feedback for Learning to Perform Short Rhythms with Expressive Variations in Timing and Loudness." Journal of New Music Research 37 (3): 207-220. doi:10.1080/09298210802322401.

Savage, J. 2009. "Pedagogical Strategies for Change." In Music Education with Digital Technology, edited by J. Finney and P. Burnard, 142-155. London: Continuum.

Schippers, H. 2006. “'As If a Little Bird Is Sitting on Your Finger ... ': Metaphor as a Key Instrument in Training Professional Musicians." International Journal of Music Education 24 (3): 209-217. doi:10.1177/ 0255761406069640.

Schmidt, R. A. 2008. "Principles of Practice for the Development of Skilled Actions: Implications for Training and Instruction in Music." In Art in Motion. Musical and Athletic Motor Learning and Performance, edited by A. Mornell, 41-67. Frankfurt am Main: Peter Langer.

Schnebly-Black, J., and S. Moore. 2003. The Rhythm Inside: Connecting Body, Mind, and Spirit through Music. Van Nuys, CA: Alfred Music.

Schnebly-Black, J., and S. Moore. 2004. Rhythm: One on One: Dalcroze Activities in the Private Music Lesson. Van Nuys, CA: Alfred Publishing Company. 
Schoonderwaldt, E., K. Falkenberg Hansen, and A. Askenfeld. 2004. "IMUTUS-An Interactive System for Learning to Play a Musical Instrument." Paper presented at the International Conference of Interactive Computer Aided Learning, Villach, Austria, September 23-25.

Schroeder, F., and I. Newland. 2013. "The Musical Body - Devising a Choreo-musical Interpretation for the Work Tierkreis (1974-75) by Karlheinz Stockhausen.” In Nine Ways of Seeing a Body, edited by S. Reeve, 99-109. Axminster: Triarchy Press.

Shernoff, D. J., M. Csikszentmihalyi, B. Shneider, and E. S. Shernoff. 2003. "Student Engagement in High School Classrooms from the Perspective of Flow Theory." School Psychology Quarterly 18 (2): 158-176. doi:10.1521/ scpq.18.2.158.21860.

Sweller, J., J. J. G. Van Merrienboer, and F. G. W. C. Paas. 1998. "Cognitive Architecture and Instructional Design." Educational Psychology Review 10 (3): 251-296. doi:10.1023/A:1022193728205.

Taylor, D. 1989. "Physical Movement and Memory for Music." British Journal of Music Education 6 (3): 251-260. doi:10.1017/S026505170000721X.

Thorpe, W. 2002. "Visual Feedback of Acoustic Voice Features in Singing Training." Paper presented at the 9th Australian Speech Science \& Technology Conference, Melbourne, Australia, December 3-5.

Tsukerman, V. D. 2016. “The Neurodynamic Bases of Imitating Learning and Episodic Memory.” Biophysics 61 (2): 316-325. doi:10.1134/S0006350916020226.

Upitis, R., J. Brook, and P. C. Abrami. 2014. "Enhancing Music Learning with Digital Tools: A Case Study of a Student Using iSCORE." Journal of Literature and Art Studies 4 (6): 489-497. doi:10.17265/2159-5836/2014.06.008.

Urista, D. 2016. The Moving Body in the Aural Skills Classroom: A Eurhythmics Based Approach. New York, NY: Oxford University Press.

Van den Beemt, A., S. Akkerman, and P. R. J. Simons. 2011. "Patterns of Interactive Media Use among Contemporary Youth." Journal of Computer Assisted Learning 27 (2): 103-118. doi:10.1111/j.1365-2729.2010.00384.x.

Van Der Linden, J., E. Schoonderwaldt, J. Bird, and R. Johnson. 2011. "Musicjacket: Combining Motion Capture and Vibrotactile Feedback to Teach Violin Bowing." IEEE Transactions on Instrumentation and Measurement 60 (1): 104-113. doi:10.1109/TIM.2010.2065770.

Van Der Merwe, L. 2015. "The First Experiences of Music Students with Dalcroze-inspired Activities: A Phenomenological Study." Psychology of Music, 43 (3): 390-406. doi:10.1177/0305735613513485.

Van Merriënboer, J. J. G., and P. A. Kirschner. 2012. Ten Steps to Complex Learning: A Systematic Approach to FourComponent Instructional Design. London: Routledge.

Wang, D. P.-C. 2008. "The Quantifying Analysis of Effectiveness of Music Learning Through the Dalcroze Musical Method." US-China Education Review 5: 32-41.

Washburn, K. D. 2010. The Architecture of Learning. Designing Instruction for the Learning Brain. Pelham, AL: Clerestory Press.

Wedin, E. 2015. Playing Music with the Whole Body. Eurhythmics and Motor Development. Stockholm, SE: Gehrmans Musikförlag.

Welch, G. F., D. M. Howard, E. Himonides, and J. Brereton. 2005. "Real-Time Feedback in the Singing Studio: An Innovatory Action-Research Project Using New Voice Technology." Music Education Research 7 (2): 225-249. doi:10.1080/14613800500169779.

Wilson, P. H., K. Lee, J. Callaghan, and W. Thorpe. 2008. "Learning to Sing in Tune: Does Real-time Visual Feedback Help?” Journal of Interdisciplinary Music Studies 2 (1-2): 157-152. doi:10.1007/s00426-010-0291-6.

Wise, S., J. Greenwood, and N. Davis. 2011. "Teachers' Use of Digital Technology in Secondary Music Education: Illustrations of Changing Classrooms." British Journal of Music Education 28 (2): 117-134. doi:10.1017/ S0265051711000039.

Woody, R. 2007. "Popular Music in School: Remixing the Issues." Music Educators Journal 93 (4): 32-37. doi:10.1177/ 002743210709300415.

Woszczynski, A., P. Roth, and A. Segars. 2002. "Exploring the Theoretical Foundations of Playfulness in Computer Interactions." Computers in Human Behavior 18 (4): 369-388. doi:10.1016/S0747-5632(01)00058-9.

Wulf, G., and R. Lewthwaite. 2009. "Attentional and Motivational Influences on Motor Performance and Learning." In Art in Motion: Musical and Athletic Motor Learning and Performance, edited by A. Mornell, 95-117. Frankfurt am Main: Peter Lang.

Xiao, X., P. Puentes, E. Ackermann, and H. Ishii. 2016. "Andantino: Teaching Children Piano with Projected Animated Characters." In Proceedings of the 15th International Conference on Interaction Design and Children, edited by Janet Read and Phil Stenton, 37-45. New York, NY: ACM.

Young, V., K. Burwell, and D. Pickup. 2003. "Areas of Study and Teaching Strategies Instrumental Teaching: A Case Study Research Project.” Music Education Research 5 (2): 139-155. doi:10.1080/1461380032000085522.

Yu, P.-T., Y.-S. Lai, H.-H. Tsai, and Y.-H. Chang. 2010. "Using a Multimodal Learning System to Support Music Instruction." Journal of Educational Technology \& Society 13 (3): 151-162. http://www.jstor.org/stable/ jeductechsoci.13.3.151. 


\section{Appendix}

In this appendix, three exercises are described, combining the use of the MPM with Dalcroze-inspired activities. The design of the exercises is based on the teaching experience gained from a classroom study with the MPM (Nijs and Leman 2014), on workshops with the system at music educational seminars and conferences, and on the hands-on courses provided at the Royal Conservatory The Hague (NL) and LUCA School of Arts (Leuven, BE).

\section{Exercise 1 - a group lesson with the MPM}
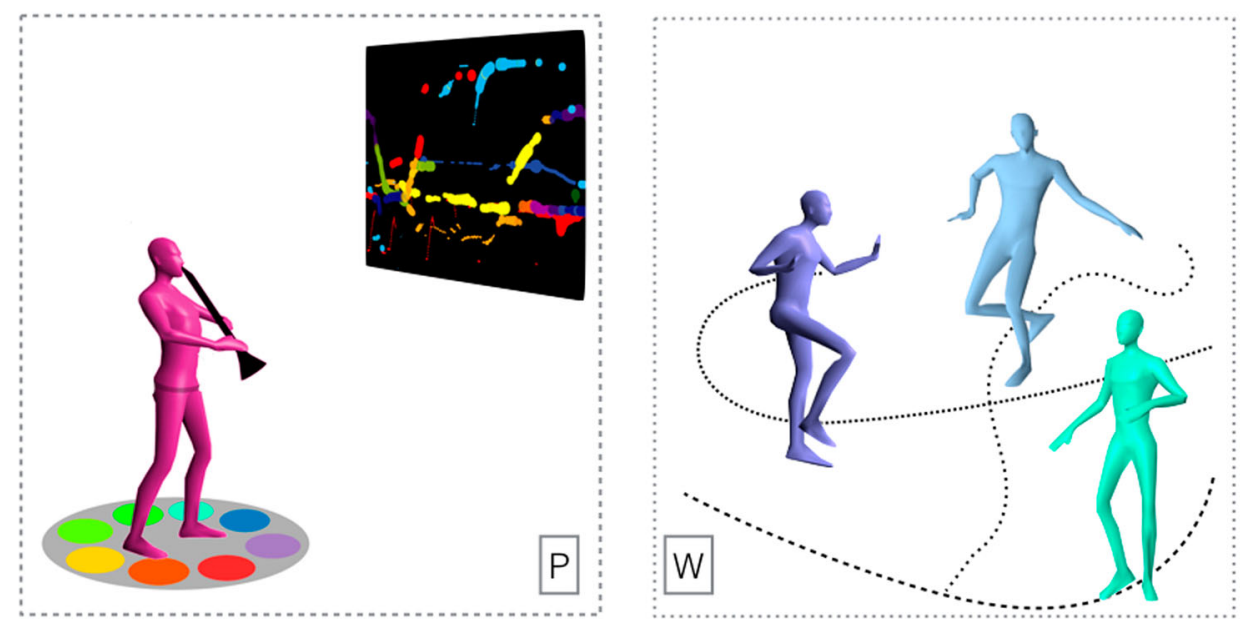

\section{Explanation}

In this exercise, different perspectives to music are explored through the combination of movement, music and a 'painting'. One student engages with the MPM while the others engage in a typical Dalcroze exercise of walking while showing an individually chosen rhythm in the steps. Based on the motto 'show what you see', one walking student is selected by the student who engages with the MPM to use his/her rhythm as a source of inspiration to engage with the MPM (improvise with body and music and as such make a painting). Here the added value of the visual component lies in the fact that the student engages in an interactive loop between different modalities as sources of information.

Number of participants: 6-10.

\section{Procedure}

(1) A few students (W) start walking around in the classroom, each performing (by stepping) an individually chosen rhythm. The teacher accompanies the walking with a drum (accompaniment must be without pitch, not to confuse the pitch tracking of the MPM).

Note: here, the teacher can provide 'game cards' displaying certain rhythms, taken from a new musical work that later will be presented to the students. In this way, learning to play this musical work is prepared and students can recall their experience of the different rhythms.

(2) One student ( $\mathrm{P}$ ) engages with the MPM, being located on the coloured pressure-sensing mat.

(a) First, this student looks at the walking students and picks out one student's rhythm.

(b) Then, this rhythm is used as the basis for improvising (on an instrument or singing) a melody and making a painting with it $(\mathrm{W} \rightarrow \mathrm{P})$.

(3) Then, the students who were walking need to guess which student was picked out $(\mathrm{P} \rightarrow \mathrm{W})$.

(4) Next, the students perform this rhythm together, walking around in the classroom, possibly accompanied by the piano or singing together the melody.

(5) Then, a student (possibly the same as before) engages again with the MPM, and is asked to adapt the painting to the expressive character of the other students who switch (when a sign is given by the teacher) between for example a fluent and a jerky version of stepping the rhythm $(\mathrm{W} \rightarrow \mathrm{P})$.

(6) After this exercise, a moment of reflection follows in which the music-movement-painting connection is discussed. 


\section{Extension}

This exercise can be modified to introduce another dimension by starting from the 'painting'. Here, a few students leave the classroom and come back after Step 2 in the above-described procedure. Then these students are asked to guess what rhythm could have been the basis for the painting (possible also asking to sing the melody) and to walk around showing their rhythmic interpretation of the painting. Afterwards, the student whose rhythm was actually chosen, walks around and shows it.

This extension is an ideal way to introduce and explore the concept of variation. The students that start from the painting often perform a slight modification to the original rhythm. Performing and switching between the interpreted rhythms and the original rhythm makes students experience the variation in a bodily way and learn to see how it changes the music, when improvising on both rhythms.

\section{Exercise 2 - controlling the controller}

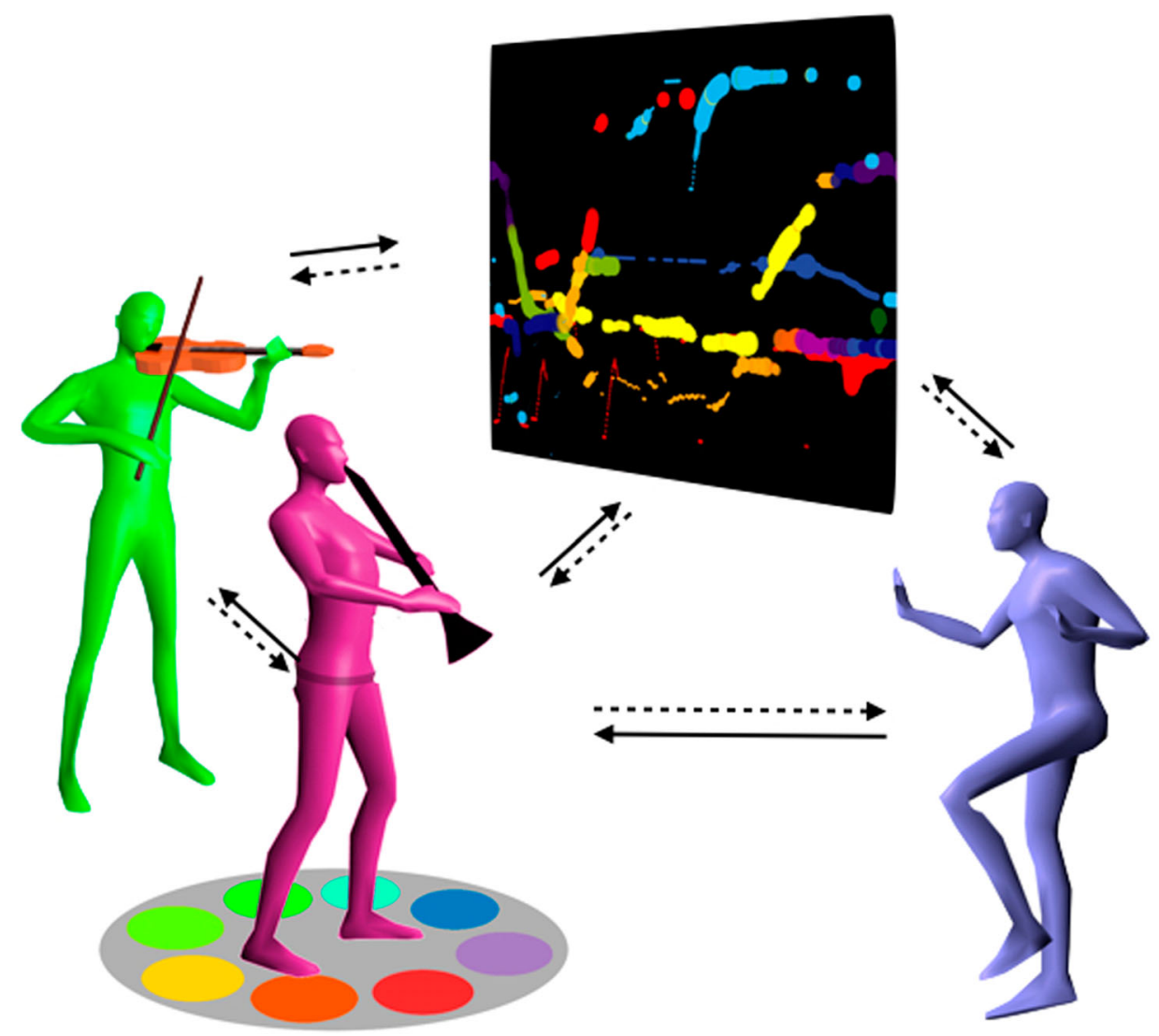

\section{Explanation}

The core idea of this exercise is that a student's actions while engaging with the MPM are partially determined by other students. In this way, the 'painting' becomes a product of joint action. But because the painting is the result of music and movement, this exercise also leads to a kind of choreo-musical outcome. Interestingly, everybody engages in an interactive loop with music, movement and visuals and can - inspired by whatever catches attention - influence the outcome.

Number of participants: $3-4$.

\section{Procedure}

(1) Students decide on who engages with the MPM.

(2) Students discuss the different control parameters (e.g. drawing direction, pitch and colour) and how different options (e.g. left vs. right, certain notes and different colours) can be triggered. 
Note 1: Here, showing 'what you SEE' and 'what you HEAR' can be combined or implemented separately, depending on the level of the students

Note 2: the students who control the student that engages with the MPM most often make use of a limited set of triggers. Consequently, in this exercise students with different skill levels can participate. For example, when triggering a control parameter with sound they can play loud or soft, or change between a limited number of notes. When triggering a control parameter with movement, they can move fluently (e.g. to trigger legato or consecutive notes) or jerky (e.g. to trigger staccato or larger intervals between notes).

(3) One student (P) starts engaging with the MPM. Other students join and, according to their own creative and expressive intentions, invite the student that engages with the MPM to change her playing on the basis of the agreed triggers.

\section{Exercise 3 - metre switcher}
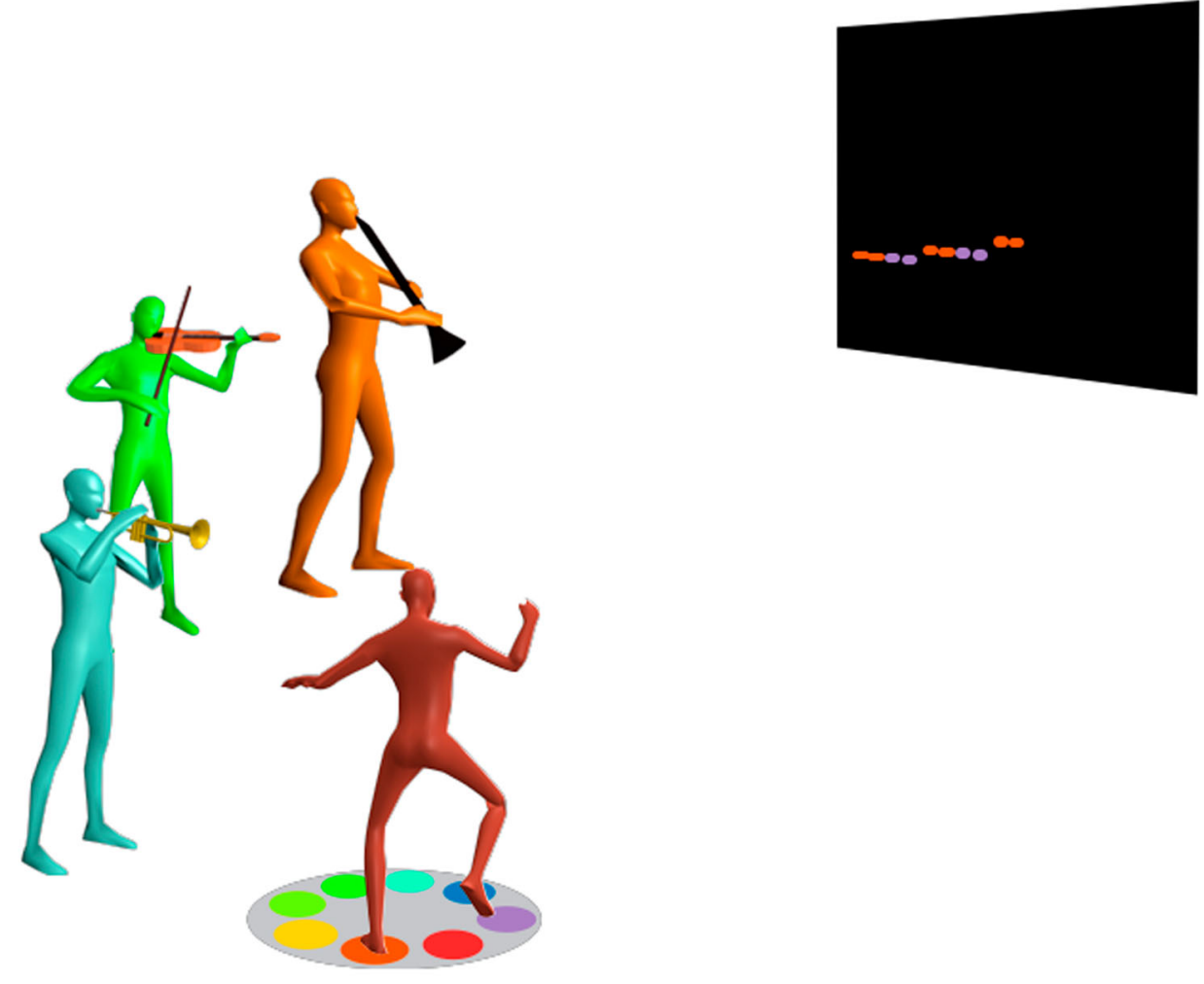

\section{Explanation}

A typical Dalcrozian method is switching between two bodily responses in accordance to the music, very often alternating between stepping and clapping/conducting. In this exercise only non-locomotor movements are used and all students look at the screen while playing together. In this way the visual output can support the execution and switching of bodily responses.

\section{Procedure}

(1) Students decide on who will stand on the mat and trigger the colours

(2) The teacher presents a rhythm (e.g. 'quaver-crotchet-quaver-crotchet-crotchet' in 4/4 time) to the students (playing it on the piano or any other instrument) and asks them to play it a few times on one note, to get acquainted with it. Possibly students can walk around while playing this rhythm.

(3) Then students are asked to play the macro-beats on the same note (4 crotchets in $4 / 4$ time)

(4) Next, all students, except the student on the mat, play a scale together repeating each note 4 times (macro-beats). The student on the mat triggers a colour for each beat. 
Note 1: the student on the mat can possibly join the others in playing the scale. This is difficult and should be built up from very easy tasks.

Note 2: the other students can play or use a combination of playing with additional stepping patterns. For example, switch between a semibreve (duration $=4$ beats) and a minim (duration $=2$ beats) to more difficult (e.g. switch between the presented rhythm and the micro-beats).

(5) At a sign of the teacher, the students switch to the chosen rhythm.

\section{Extension 1}

A possible way to vary this exercise is by using two sets of colours, whereby the switching of the student on the mat between the sets is the sign for the other students to switch between responses. Here the student who triggers the colours can keep on stepping the macro-beats.

\section{Extension 2}

Another way to vary this exercise is asking the student on the colour mat to step the rhythm with different colours for each note, while the other students play the macro-beats. And vice versa.

For more exercises: see Identifying URL 